\title{
Ligand effect on the cationic palladium complexes in polymerization of vinyl ethers
}

\author{
Yi-Chun Chen, K. Rajender Reddy, Shiuh-Tzung Liu* \\ Department of Chemistry, National Taiwan University, Taipei 106, Taiwan, ROC
}

Received 15 October 2001; received in revised form 29 March 2002; accepted 16 May 2002

\begin{abstract}
A series of cationic palladium complexes have been used as catalysts on the polymerization of vinyl ethers in excellent yields. The key feature of this study indicates how the ligand donors as well as the cationic nature influence the reactivity of the palladium center in the polymerization of vinyl ethers. It was found that the $\pi$-acidic character of imine donors does increase the activity of palladium metal center which catalyzes the cationic polymerization of vinyl ether, whereas the palladium center coordinated with bisphosphine ligand is completely inactive for the polymerization. (C) 2002 Elsevier Science B.V. All rights reserved.
\end{abstract}

Keywords: Palladium; Imine; Polymerization; Vinyl ether; Phosphine

\section{Introduction}

Utilization of Lewis acid to catalyze carbocationic polymerization of vinyl ethers is well-documented due to the resonance stabilization of carbocation via lone pair electrons on the oxygen [1]. Some structurally welldefined early transition-metal complexes do behave as Lewis acids to catalyze the polymerization of electronrich olefins [2,3], but late transition metal complexes are rarely reported [4-6]. Recently, Brookhart and coworkers found that the diimine palladium complexes catalyze the polymerization of vinyl ethers [4], whereas Eisenberg's group reported that the related $C_{2}$-symmetrical diimine platinum complexes have similar activity[3]. However, information concerning the influence of ligand in palladium-catalyzed polymerization of electron-rich olefins is not quite clear. Here we disclose our investigation on the reactivity of a series of palladium complexes $\mathbf{1}-\mathbf{3}$ in polymerization towards various vinyl ethers (Scheme 1).

\footnotetext{
* Corresponding author. Tel.: +886-2-2366-0352; fax: +886-22363-6359

E-mail address: stliu@ccms.ntu.edu.tw (S.-T. Liu).
}

\section{Results and discussion}

In a typical experiment for the polymerization, a mixture of ethyl vinyl ether $(2 \mathrm{ml})$ and $\mathbf{1 a}(30 \mathrm{mg})$ in dichloromethane $(5 \mathrm{ml})$ was stirred at room temperature. After the reaction was stopped, the mixture was concentrated and the residue was filtered through silica gel eluting with ethyl acetate-chloroform $(\mathrm{V}: \mathrm{V}=4: 1)$. Upon concentration, the viscous material was obtained and analyzed by NMR and GPC. Results are summarized in Table 1. It appears that the complete conversion of monomer into polymer requires $12 \mathrm{~h}$ and the longer reaction time has little effect on the polymerization. However, the concentration of monomer affects the yield as well as molecular weight significantly (entries 7 and 8). The higher concentration of substrate makes the reaction medium much more viscous during the polymerization which presumably limits the growth of longer polymer chain. The molecular weight of poly(vinyl ether) prepared in this manner can be up to 11000 which is quite similar to that reported by Eisenberg and coworkers in utilizing of diimine-platinum(II) complex as a catalyst [5]. It is also noticed that a higher molecular weight of polymer was obtained when the reaction was carried out at raised temperature (entry 4). Based on the method described by Matsuzaki [8], the ratio of the meso form $(m)$ versus the racemic ones $(r)$ for the 


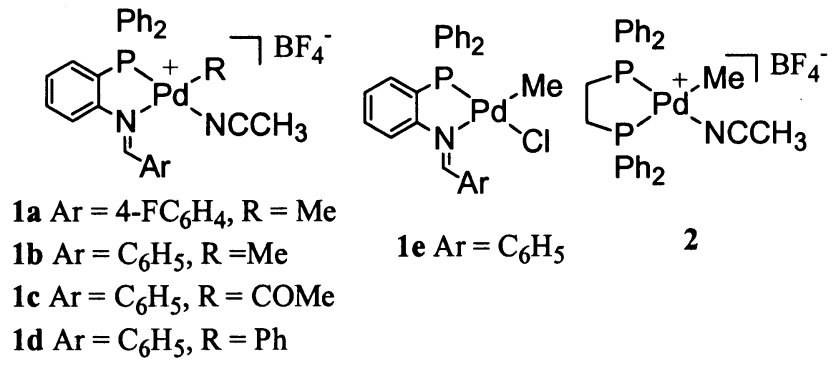

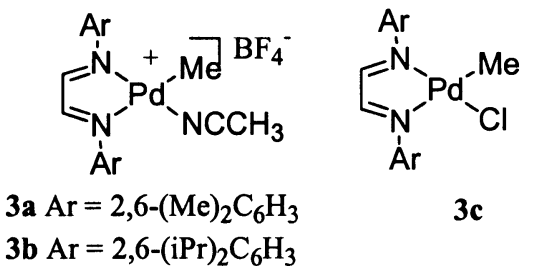

Scheme 1. Various palladium complexes as catalysts for polymerization.

adjacent insertion units is about $45: 55$, indicating the poly(vinyl ether) being an atactic polymer. This outcome is slightly different from those polymers prepared by using the diimine-platinum complex as a catalyst [5].

In addition to $\mathbf{1 a}$, the related complex $\mathbf{1 b}$ is also a good catalyst (entry 9). Complexes with various carbon ligand on palladium center are active for the polymerization of vinyl ether. The phenyl-substituted complex 1d catalyze the polymerization of ethyl vinyl ether to provide the polymer with $\mathrm{M}_{n}=9986$, which is similar to those obtained by both complexes $\mathbf{1 a}$ and $\mathbf{1 b}$. However, the molecular weight of polymer obtained via the catalysis of acyl-substituted complex 1c appears to be smaller (entry 10). Analysis of the end group of the polymer chain was achieved by the typical procedure reported by Loontjens and coworkers [9]. The ${ }^{1} \mathrm{H}-\mathrm{NMR}$ spectrum of the polymer shows an ethoxy-acetal functionality with the resonance at ca. $\delta 4.5$ for the methine proton of $-\mathrm{CH}\left(\mathrm{OCH}_{2} \mathrm{CH}_{3}\right)_{2}$. This observation is clearly consistent with a cationic polymerization pathway. Additionally, it is known that $\beta$-proton elimination by counterions takes place on the cationic polymerization of vinyl ethers. Chemical shifts at ca. $\delta 5.3$ and 5.6 with very weak intensity corresponding to the olefinic protons also appear on the spectrum, which further illustrates the cationic route for polymerization.

It is an interesting finding that the chelating donors affect dramatically on the polymerization activity of the palladium complexes. Bis-phosphine (dppe) chelated cationic palladium complex $\mathbf{2}$ shows no catalytic activity at all (entry 13), but the diimine-complexes (Brookhart catalysts) appear higher activities toward the vinyl ether (entries 14 and 15). Under similar reaction conditions, complex $\mathbf{3 b}$ gives quantitative conversion of monomer into polymer within $0.25 \mathrm{~h}$ with the $\mathrm{M}_{n}=21770$, which is even higher than those complexes $[\mathrm{Pd}(\mathrm{P}-\mathrm{N}) \mathrm{MeL}]^{+}$ studied. The less steric hindered substituted diimine palladium complex $\mathbf{3 a}$ is also an excellent catalyst for the polymerization, but appears to be less reactive than complex $\mathbf{3 b}$. This trend is similar to those reported by Brookhart et al. in polymerization of ethylene [4].

Unlike the cationic palladium complexes, the neutral complexes $\mathbf{1 e}$ and $\mathbf{3 c}$ appear no catalytic activity in the polymerization of vinyl ether. This observation clearly indicates the requirement of cationic nature in promotion of the polymerization of the vinyl ether. That cationic palladium complexes are the intiators for the polymerization, which is in agreement with that reported by Eisenberg and coworkers in cationic platinum complex catalyzed polymerization [5]. As for the activity differences among 1-3, we believed that the influence of donor atoms play the key role. It is known that both

Table 1

Polymerization of ethyl vinyl ether catalyzed by palladium catalysts

\begin{tabular}{|c|c|c|c|c|c|c|c|}
\hline Entry & Catalyst & Vinyl ether (ml) & $T\left({ }^{\circ} \mathrm{C}\right)^{\mathrm{a}}$ & $t(\mathrm{~h})$ & Yield (\%) & $\mathrm{M}_{n}\left(\times 10^{2}\right)$ & $\mathrm{M}_{w} / \mathrm{M}_{n}$ \\
\hline 1 & 1a & 2 & $\mathrm{RT}$ & 6 & 7 & 9 & 2.68 \\
\hline 2 & 1a & 2 & $\mathrm{RT}$ & 12 & $>99$ & 117 & 1.86 \\
\hline 3 & $1 \mathrm{a}$ & 2 & RT & 24 & $>99$ & 117 & 1.79 \\
\hline 4 & 1a & 2 & reflux & 24 & $>99$ & 150 & 2.15 \\
\hline 5 & $1 \mathrm{a}$ & 2 & RT & 72 & 98 & 105 & 1.82 \\
\hline 6 & $1 \mathrm{a}$ & 4 & RT & 24 & $>99$ & 102 & 2.15 \\
\hline 7 & 1a & 6 & $\mathrm{RT}$ & 24 & 73 & 810 & 2.02 \\
\hline 8 & $1 \mathrm{a}$ & 8 & $\mathrm{RT}$ & 24 & 76 & 76 & 2.18 \\
\hline 9 & 1b & 2 & $\mathrm{RT}$ & 20 & 94 & 140 & 2.24 \\
\hline 10 & 1c & 2 & $\mathrm{RT}$ & 45 & 99 & 35 & 2.57 \\
\hline 11 & 1d & 2 & RT & 24 & 88 & 100 & 2.35 \\
\hline 12 & 1e & 2 & RT & 24 & 0 & & \\
\hline 13 & 2 & 2 & $\mathrm{RT}$ & 20 & 0 & & \\
\hline 14 & $3 a$ & 2 & $\mathrm{RT}$ & 0.5 & 85 & 174 & 2.12 \\
\hline 15 & 3b & 2 & $\mathrm{RT}$ & 0.25 & 100 & 218 & 2.44 \\
\hline
\end{tabular}

\footnotetext{
${ }^{\text {a }}$ Reaction temperature.
} 
imine and phosphine ligands are good $\sigma$-donors. However, the imine donors allow its late-transition metal complexes to increase the electrophilic character [4]. Thus the palladium complexes coordinated with imine ligands would be more reactive towards vinyl ethers in the polymerization than those coordinated with phosphines.

Other related monomers such as butyl vinyl ether, 2,3dihydrofuran, 2,3-dihydro-4H-pyran and $\mathrm{N}$-vinylcarbazole (NVC) can be polymerized by the cationic iminepalladium complexes and the results are summarized in Table 2 [10]. In all instances, the reactions proceed smoothly to provide the corresponding polymer in excellent yields, except trimethylsilyl vinyl ether. The polymer of NVC obtained by the cationic palladium complex is in lower molecular weight, but better $\mathrm{M}_{w} /$ $\mathrm{M}_{n}$, which is quite different from the preparation by using the platinum complex [5]. As for 2,3-dihydro-4Hpyran, the polymer was obtained as a copolymer $\mathbf{4}$ due to the combination of the ring-opening and six-member ring units of pyran, which is similar to the cationic polymerization reported by Nuyken [10]. However, this kind of ring opening reaction does not appear in the furan frame.

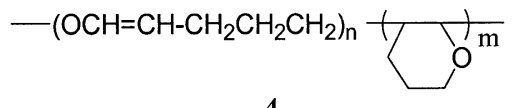

4

\section{Conclusion}

The present result reveals that the cationic palladium complexes with imine ligands do assist the polymerization of vinyl ethers. However, the activity of the metal center is found to be a function of the donor atoms, and qualitatively they are in the order of $\mathrm{N}-\mathrm{N}>\mathrm{P}-\mathrm{N} \gg \mathrm{P}-$ $\mathrm{P}$. This result indicates that the $\pi$-acidic character of imine donor does increase the activity of metal center in cationic polymerization [5,9]. As compared with the known Lewis acid catalyst or early transition metal catalysts, the late-transition metal catalysts in polymer- ization of vinyl ether do provide better control in molecular weights in high conversions under mild and neutral condition, even without using initiator. Further studies on the relative activity of palladium center as a function of ligands are presently under investigation.

\section{Experimental}

\subsection{General}

Solvents were dried by standard procedures. IR spectra were recorded on a Bio-Rad FTS-40 spectrophotometer. The NMR spectra were recorded on a Bruker ACE-200 or a ACE-300 spectrometer. For the ${ }^{31} \mathrm{P}-\mathrm{NMR}$ spectra, the spectrometer frequency at 81.015 $\mathrm{MHz}$ or $121.49 \mathrm{MHz}$ was employed and chemical shifts are given in ppm $(\delta)$ relative to $85 \% \mathrm{H}_{3} \mathrm{PO}_{4}$ in $\mathrm{CDCl}_{3}$. Values upfield of the standard are defined as negative. The corresponding frequencies for ${ }^{13} \mathrm{C}-\mathrm{NMR}$ spectra were at 50.32 or $75.47 \mathrm{MHz}$ for respective spectrometers. Mass spectrometric analyses were collected on a JEOL SX-102A spectrometer. Elemental analyses were done on a Perkin-Elmer $2400 \mathrm{CHN}$ analyzer. Preparation of $\mathbf{1 a}$ and $\mathbf{1 b}$ was similar to those procedures described previously [7]. Gel permeation chromatography (GPC) data were obtained from a Waters Model 590 liquid chromatograph installed with a Lab Allience RI 2000 detector using THF as eluant at room temperature and polystyrene calibration curve for analyses. Differential scanning calorimetric (DSC) measurement was carried out on a TA 2920 system.

\subsection{Polymerization of vinyl ethers}

To a $25 \mathrm{ml}$ two-necked round bottle was placed with catalyst (30 mg, $\sim 4.7 \times 10^{-2} \mathrm{mmol}$ ), which was evacuated and flashed with nitrogen three times. Vinyl ether $(2 \mathrm{ml})$ was syringed into the flask. The flask was cooled to $-78{ }^{\circ} \mathrm{C}$ and then evacuated followed by pressurizing with helium. Upon warming to room temperature (r.t.), dichloromethane $(5 \mathrm{ml})$ was added and the resulting mixture was stirred. After the reaction

Table 2

Polymerization of vinyl ethers

\begin{tabular}{|c|c|c|c|c|c|c|c|}
\hline Entry & Catalyst & Monomer $^{\mathrm{a}}$ & $T\left({ }^{\circ} \mathrm{C}\right)^{\mathrm{b}}$ & $t(\mathrm{~h})$ & Yield $(\%)$ & $\mathrm{M}_{n}\left(\times 10^{2}\right)$ & $\mathrm{M}_{w} / \mathrm{M}_{n}$ \\
\hline 1 & 1a & $n-\mathrm{BuOCH}=\mathrm{CH}_{2}$ & RT & 24 & 100 & 103 & 1.99 \\
\hline 2 & 1a & 2,3-dihydrofuran & RT & 24 & 96 & 110 & 1.65 \\
\hline 3 & $3 a$ & $n-\mathrm{BuOCH}=\mathrm{CH}_{2}$ & RT & 0.5 & 100 & 176 & 3.2 \\
\hline 4 & $3 b$ & 2,3-dihydrofuran & RT & 24 & 100 & 108 & 1.60 \\
\hline 5 & 1a & $\mathrm{Me}_{3} \mathrm{SiOCH}=\mathrm{CH}_{2}$ & RT & 24 & & & \\
\hline 6 & $1 \mathrm{a}$ & 2,3-dihydro-4H-pyran & RT & 120 & $>99 \%$ & 66 & 1.20 \\
\hline
\end{tabular}

\footnotetext{
${ }^{\text {a }}$ Two milliliter of monomer used.

${ }^{\mathrm{b}}$ Reaction temperature.
} 
was completed, the reaction mixture was concentrated. The residue was passed through silica gel column with elution of ethyl acetate-chloroform. The desired polymer was obtained upon concentration. All results are summarized in Tables 1 and 2.

\subsubsection{Poly (ethyl vinyl ether)}

${ }^{1} \mathrm{H}-\mathrm{NMR} \delta 3.62(\mathrm{br}, 1 \mathrm{H}, \mathrm{O}-\mathrm{CH}-), 3.49(\mathrm{br}, 2 \mathrm{H}, \mathrm{O}-$ $\left.\mathrm{CH}_{2}-\right), 1.601 .80\left(2 \mathrm{H},-\mathrm{CH}_{2}-\right), 1.20\left(\mathrm{t}, 3 \mathrm{H},-\mathrm{CH}_{3}\right)$; ${ }^{13} \mathrm{C}-\mathrm{NMR} 73.7\left(\mathrm{OCH}_{2}\right), 64.1(\mathrm{OCH}-), 40.5\left(-\mathrm{CH}_{2}-\right)$, $15.6\left(-\mathrm{CH}_{3}\right) ; T_{\mathrm{g}}:-34.2{ }^{\circ} \mathrm{C}$; Anal. Calc. for $\mathrm{C}_{4} \mathrm{H}_{8} \mathrm{O}: \mathrm{C}$, $66.63 ; \mathrm{H}, 11.18$. Found: $\mathrm{C}, 66.70 ; \mathrm{H}, 10.80 \%$.

\subsubsection{Poly(butyl vinyl ether)}

${ }^{1} \mathrm{H}-\mathrm{NMR} \delta$ 3.36-3.44 (br, $3 \mathrm{H}, \mathrm{O}-\mathrm{CH}-$ and $\mathrm{O}-$ $\mathrm{CH}_{2}-$ ), $1.31-1.78$ (br, $6 \mathrm{H},-\mathrm{CH}_{2}-$ and $-\mathrm{CH}_{2} \mathrm{CH}_{2}-$ ), 0.85-0.88 (br, $3 \mathrm{H})$; ${ }^{13} \mathrm{C}-\mathrm{NMR} \quad \delta 73.7$ (OCH-), 68.7 $\left(\mathrm{OCH}_{2}-\right)$, $40.5\left(-\mathrm{CH}_{2}-\right)$, 32.4, $19.4\left(-\mathrm{CH}_{2}-\right)$, $13.8\left(-\mathrm{CH}_{3}\right) ; T_{\mathrm{g}}:-59.8{ }^{\circ} \mathrm{C}$; Anal. Calc. for $\mathrm{C}_{6} \mathrm{H}_{12} \mathrm{O}$ : C, 71.95; H, 12.08. Found: C, 71.53; H, 12.34\%.

\subsection{3. $\operatorname{Poly}(2,3$-dihydrofuran)}

${ }^{1} \mathrm{H}-\mathrm{NMR} \delta 3.52-3.72\left(\mathrm{br}, 3 \mathrm{H}, \mathrm{OCH}-\right.$ and $\left.\mathrm{OCH}_{2}-\right)$, $1.85-2.33\left(\mathrm{br}, 3 \mathrm{H},-\mathrm{CH}-\right.$ and $\left.-\mathrm{CH}_{2}-\right) ;{ }^{13} \mathrm{C}-\mathrm{NMR} \delta$ 79.4-83.6 (OCH-), 65.7-67.6 $\left(\mathrm{OCH}_{2}-\right)$, 43.0-47.3 ($\mathrm{CH}-), 25.3-30.0\left(-\mathrm{CH}_{2}\right) ; T_{\mathrm{g}}: 117.2{ }^{\circ} \mathrm{C}$; Anal. Calc. for $\mathrm{C}_{4} \mathrm{H}_{6} \mathrm{O}$ C, 68.57; $\mathrm{H}, 8.57$. Found: $\mathrm{C}, 68.02 ; \mathrm{H}, 8.82 \%$.

\subsubsection{Poly (2,3-dihydro-4H-pyran)}

$\mathrm{IR}(\mathrm{KBr}) 1668 \mathrm{~cm}^{-1}(\mathrm{C}=\mathrm{C}) ;{ }^{1} \mathrm{H}-\mathrm{NMR} \delta 5.27-4.52$ (br) $3.92-3.22$ (br), 2.30-1.18(br); $T_{\mathrm{g}}$ : $21.6{ }^{\circ} \mathrm{C}$; Anal. Calc. for $\mathrm{C}_{5} \mathrm{H}_{8} \mathrm{O}$ C, 71.43; H, 9.52. Found: $\mathrm{C}, 69.73 ; \mathrm{H}$, $9.78 \%$.

\section{Acknowledgements}

Financial support for this work from the National Science Council (NSC90-2113-M002-038) Taiwan, $\mathrm{ROC}$, is acknowledged.

\section{References}

[1] (a) For recent reviews: M. Sawamoto, T. Higashimura, Makromol. Chem. Macromol. Symp. 60 (1992) 47;

(b) J.P. Kennedy, Macromol. Chem. 1 (1990) 260;

(c) K. Kazanskii, Makromol. Chem. Macromol. Symp. 60 (1992) 259

(d) S. Aoshima, E. Kobayashi, Makromol. Chem. Macromol. Symp. 95 (1995) 91;

(e) C.S. Patrickios, C. Forder, S.P. Armes, N.C. Billingham, J. Polym. Sci., Part A: Polym. Chem. 35 (1997) 1181;

(f) C. Pugh, A.L. Kiste, Prog. Polym. Sci. 22 (1997) 601;

(g) S. Spange, U. Eismann, S. Hoehne, E. Langhammer, Macromol. Symp. 126 (1998) 223;

(h) K. Yamada, M. Miyazaki, K. Ohno, T. Fukuda, M. Minoda, Macromolecules 32 (1999) 290;

(i) T. Higashimura, M. Sawamoto, in: G.C. Eastmond, A. Ledwith, S. Russo, P. Sigwait, (Eds.) Comprehensive Polymer Science; Pergamon Press; New York, 1989, vol. 3, p. 673;

(j) R. Faust, Macromol. Symp. 157 (2000) 101.

[2] (a) S. Ingrisch, O. Nuyken, M.K. Mishra, Plast. Eng. 53 (1999) 77; (b) K. Satoh, M. Kamigaito, M. Sawamoto, Macromolecules 32 (1999) 3827;

(c) M. Ouchi, M. Kamigaito, M. Sawamoto, Macromolecules 32 (1999) 6407;

(d) S. Hadjikyriacou, R. Faust, Macromolecules 32 (1999) 6393.

[3] Q. Wang, M.C. Baird, Macromolecules 28 (1995) 8021

[4] S.D. Ittel, L.K. Johnson, M. Brookhart, Chem. Rev. 100 (2000) 1169 (and references therein).

[5] P. Albietz, Jr., K. Yang, R. Eisenberg, Organometallics 18 (1999) 2747.

[6] (a) S. Turner, P. MacKenzie, C. Killian, J. McDevitt, A. Jones, J. Ponasik, WO Patent Application 9837110 to Eastman, priority date Aug 27, 1998;

(b) S.D. Arthur, L.K. Johnson, E.F. McCord, P.A. Morken, L. Wang, Y. Wang, WO Patent Application 9905189 to DuPont, priority date July 23, 1997;

(c) U. Klabunde, US Patent 4698403, Oct 6, 1987; US Patent 4716205, Dec 29/87; US Patent 4906754, March 6/90; US Patent 5030606, July 9, 1991; US Patent 5175326, Dec 29, 1992 all to DuPont.

[7] (a) K.R. Reddy, C.-L. Chen, Y.-H. Liu, S.-M. Peng, J.-T. Chen, S.-T. Liu, Organometallics 18 (1999) 2574

(b) K.R. Reddy, K. Surekha, G.-H. Lee, S.-M. Peng, J.-T. Chen, S.-T. Liu, Organometallics 21 (2001) 1292

(c) Y.-C. Chen, C.-L. Chen, J.-T. Chen, S.-T. Liu, Organometallics 21 (2001) 1285.

[8] K. Matsuzaki, H. Ito, T. Kawamura, T. Uryu, J. Polym. Sci. Polym. Chem. Ed. 11 (1979) 971

[9] T. Loontjens, F. Derks, E. Kleuskens, Polym. Bull. 27 (1992) 519.

[10] O. Nuyken, S. Aechtner, Polym. Bull. 28 (1992) 117. 